type was insufficiently full even before the patient tried to elicit the reflex arc of the bladder it did not succeed. On the contrary, if he waited long enough in order to elicit stretch reflex until a certain point it would be much easier for him to empty his bladder.

Dr. Pool, adding to the point, said if one looked at this reflex which he thought was also possible in the bladder and one pressed slightly with the hands on the bladder, stretch reflex was evoked earlier and in that way the bladder of a total lesion patient was emptied. Pressure with the hand could evoke stretch reflex.

Guttmann, L., said he would like to draw attention to the importance of Dr. Pool's paper from the management point of view of paraplegics and tetraplegics with spasticity. The question was how far could one encourage the development of the stretch reflex in the legs. There was no doubt about the preponderance of the flexion synergy in the reflex return. This led, if the early management were not done properly, to increased reflex flexion contractions of the legs ending finally in flexion contractures. He had stressed again and again that in order to promote the extensor reflex, the legs in the acute stages should be kept not in flexion by putting a pillow under the knees but in extension and abduction. This position promoted and encouraged extensor response, thus diminishing the overaction of the hip and knee flexors. One could also use the stretch reflex to restore standing of paraplegic patients by the action of muscles which had their segmental innervation in the spinal cord above the level of the lesion but on the other hand were fixed with their insertion points in the paralysed part of the body, especially the pelvis. The important muscle for this was the latissimus dorsi. If a paraplegic stood in parallel bars he had a tendency to relapse in flexion. This could be overcome quite easily if the patient pulled up his pelvis by the action of his latissimus dorsi and erector spinae. This pull on the pelvis consequently resulted in a pull on the paralysed gluteal muscles and elicited an extensor reflex which promoted standing.

\title{
A NEW TURNING-TILTING BED
}

\author{
By Professor L. Guttmann, C.B.E., M.D., F.R.C.P., F.R.C.S. \\ National Spinal Injuries Centre, Stoke Mandeville Hospital, Aylesbury, England
}

THERE is general agreement that the care and management of paraplegic patients, especially in the early stages following traumatic lesions, places heavy demands on both medical and nursing staff. Pressure sores have to be avoided at all costs, and to achieve this various turning methods have been introduced. The most gentle handling so far was, of course, regular manual turning of the patient by the ward staff, but this requires, in patients with fracture-dislocations of the spine, three or four people to do this. Having regard to the high survival rate of traumatic paraplegics and tetraplegics associated with severe injuries to the chest and other parts of the body on the one hand and the increasing difficulty in all countries to get adequate nursing staff, turning beds have been introduced. The most well known is the Stryker frame and its modifications. However, as I have pointed out repeatedly, this type of turning frame has its disadvantages in the management of fracture dislocations, especially those of the thoracic and lumbar vertebrae. While in such a frame hyperextension by posture with rolls underneath the fracture, necessary to reduce the fracture-dislocation, can be achieved in the supine position, this cannot be maintained by turning the patient in the abdominal position, which is the only alternative in this type of turning bed. Thus the object of maintaining hyperextension to secure re-alignment and promote stability of the broken spine is 
defeated. Moreover, in traumatic paraplegics with associated fractures of the ribs, pelvis or long bones, and in particular patients with haemo- or pneumothorax, let alone those who are unconscious, turning on to the abdominal position is clearly too hazardous and, in general, even contra-indicated. If such patients have to maintain their recumbency in supine position day and night, due to lack of regular turning from the supine into the lateral positions, the danger of early development of pressure sores is obvious.

For some years I have had the idea of developing a turning bed on which hyperextension of traumatic paraplegics can be maintained and the patient turned from the supine into lateral position in the same way as it is done manually. I am glad to say that with the excellent co-operation and research on the part of Egerton Engineering Limited, this aim has now been achieved. Two types of bed have been constructed; one which allows turning from the supine on to lateral position; the other which in addition to this turning can also be tilted up and down. Both types had extensive trials in this Centre and it is the latter, named 'The EgertonStoke Mandeville Turning-Tilting Bed', which is demonstrated here.

The bed is constructed in mild steel tubing, and the tubes are electrically welded. The height of the bed is 2 feet 2 inches $(66 \mathrm{~cm}$.) and the bed frame is 7 feet $3^{\frac{1}{4}}$ inches by 3 feet $5^{\frac{1}{2}}$ inches $(222 \mathrm{~cm}$. by $65 \mathrm{~cm}$.). The bed is mounted on 7-inch castors which have brakes, and head and foot rails are detachable, giving easy access to the patient. The bed is constructed in such a way that it can easily be broken down for shipping quantities of beds, and at its destination can be easily re-assembled.

With its electric motors the bed can turn the patient smoothly in a few seconds by pushing the button, from supine position on to his side, to a maximum angle of $70^{\circ}$, whereby in patients with fractured spines the hyperextension is not in any way interfered with. As the motors are independent it is possible to raise the opposite side, on which the patient rests during turning, slightly. This eliminates any possibility of slipping and gives the patient an added feeling of security. Furthermore, the patient can be tilted manually by a handle head and feet down to a maximum angle of $\mathrm{I} 4^{\circ}$ (fig. I). No matter to what angle or how frequently patients are turned, they always return to the centre of the bed.

The mattress platform is divided longitudinally into two parts, each part twothirds of the bed's width and both parts being hinged at the top. This allows movement of the body to take place without compressing the surface of the mattress and thus avoids creases on the patient's body. Symmetry is retained on the bed by a low tubular rail which makes it impossible for the three sectional parts of the mattress to overlap at any point. Both the Egerton-Stoke Mandeville turningtilting bed and Egerton-Stoke Mandeville turning bed can be used in traumatic tetraplegias following fracture of the cervical spine with any type of head traction, whether it is Crutchfield, Blackburn, Cone, etc. However, at my instruction a special head traction unit has been devised, which once it has been set to the required height for the patient, will not need any further adjustment. It will allow the patient to be turned from side to side without any discontinuation of the traction cord and correct tension is maintained during the process of turning. Although the present design is still in the experimental stage it may be demonstrated here.

It will be appreciated that when the patient is turned on the bed, the head and calipers will follow a definite arc and will not revolve around the central axis 


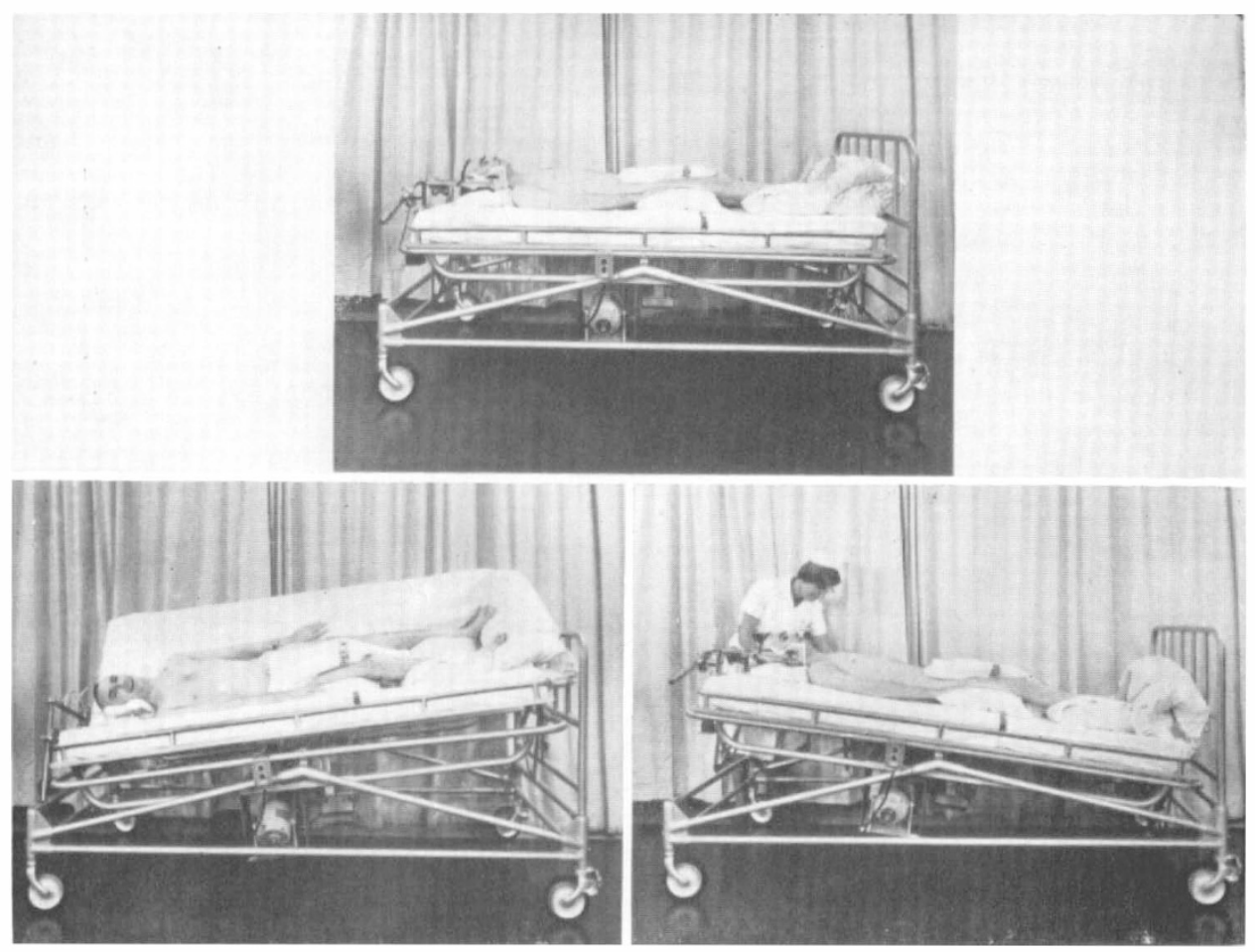

FIG. I

through the length of the body. My traction unit is designed to follow this same arc and special head pads support the head during the turning so that no special arrangements by the nursing staff are necessary when the patient is finally lying on his side. The unit consists of a pair of telescopic arms, which are mounted on a circular friction disc which are joined together at one end by a swivel link through which the traction cord passes. The unit will not allow free movement and will follow the arc made by the head caliper as the patient is turned. As I mentioned before, this traction unit is still in the experimental stage and the final device will be reported later.

The turning as well as the turning-tilting bed can, of course, also be used for the turning of patients with other severe forms of disability or disease, such as high polio cases, severe forms of rheumatoid arthritis, patients with strokes and any other severe cerebral lesions, etc.

\section{SUMMARY}

A new turning bed, called the Egerton-Stoke Mandeville Turning Bed has been devised. There are two versions of this bed-one which allows turning only from the supine to the lateral positions, and one which allows both turning as well as head-up and head-down tilting. The beds have proved successful for the management of traumatic paraplegics and tetraplegics. They can also be usefully employed in the management of other severe disabilities. 


\section{RÉSUMÉ}

Un nouveau lit tournant appelé 'Lit Egerton Stoke Mandeville' a été inventé, dont il existe deux versions, une qui ne permet que le retournement de la position en décubitus dorsal à celle de décubitus latéral, l'autre permettant les mêmes positions mais en plus l'inclinaison vers le haut ou le bas de la tête du lit. Ces deux modèles se sont révélés satisfaisants dans le traitement des cas de tétraplégie ou paraplégie traumatiques; ils peuvent aussi être utilisés dans le traitement d'autres affections sévères.

\section{ZUSAMMENFASSUNG}

Ein neues Drehbett (Egerton-Stoke Mandeville Drehbett) ist konstruiert worden. Es gibt zwei Versionen dieses Drehbetts: das eine ermöglicht Drehen des Patienten von der Rückenlage in die Seitenlage, das andre erlaubt ausserdem Herauf-und Herunterkippen des Körpers. Diese Betten haben sich in der Behandlung von traumatischen Paraplegikern und Tetraplegikern bewährt und können auch für die Behandlung von andern Schwerversehrten benutzt werden.

\section{Discussion}

Michaelis, L. S., said he would like to mention one or two points. Naturally the value of the bed was greatest for fresh lesions and in hospital. But this bed was just as suitable for some patients at home. One point might be asked: What happened to the paraplegic who was completely rehabilitated and wanted to get out of the bed ? This bed was much too high for him. It would be easy to remove the castors, which were 7 inches high, and then the upper edge of the mattress reached exactly the upper level of the average wheelchair. This meant that the patient could lift himself out of the bed into his wheelchair himself.

Harris, $P$., found the bed very ingenious and would like to ask one or two points. The prone position was not apparently used but he thought could be but would require manual help. This was interesting from the point of view of pressure being allowed to continue on the back and to some extent on the sides. He wondered whether studies had been made with relation to pressure that was permissible and occurred in these pressure areas. Also, the prone position might be useful in relation to prevention of flexor spasms and contractures of the hips and knees and also for the patient who wished to eat or write in that position.

Another point - the question of traction and especially in the early stage, if this might be required in a different direction from a straight horizontal pull, would this be possible -also counter-traction to reduce dislocations. Another point was the type of caliper which would be used. Just a year ago he had the privilege of reading a paper on Stryker frames with its modifications, which was in the current number of Paraplegia. As a surgeon, he would ask about operating upon a patient. In the Stryker frame with its modifications it was possible to operate on the head or neck, either the anteriorly or posteriorly. A further point would be about transportation of the patient. This bed was much wider than a frame. Finally, the question of price and maintenance of this bed, which was fairly elaborate and had two electrical motors.

Guttmann, L., replied that the price for the turning and tilting bed was $£ 220$, for the simple turning bed $\AA_{\mathrm{I}} 78$.

The Stryker frame was rather expensive-he thought almost the same, if not more, than the price of this bed. Therefore, it was a comparably cheap bed having regard to the advantages of the bed.

With regard to the type of calipers; any type could be used.

With regard to the prone position: this was just what they wanted to avoid for patients who were treated conservatively for fracture-dislocation. The prone position was a bad one because one just killed the purpose of one's aim by not being able to maintain the hyperextension in prone position which was necessary to re-align the fractured spine. 
With regard to prevention of pressure sores-this was the other reason why this bed had been designed. They had not had a single pressure sore by turning the patient from side to side. This was just a confirmation of his views, held since 1944, that in the acute cases there was no need to put the patient in prone position to prevent sores but if one could relieve pressure from sacrum, hips, ankles and heels by regular turning day and night from the supine to the lateral position, no pressure sores would develop.

With regard to the question whether one could operate on this bed-he thought one could operate, as far as applying the traction. As a matter of fact, in one of his first cases in 1944 with a complete lesion at C6, he did the caliper traction in the ward on an ordinary hospital bed because the patient was so ill. One could use any bed, if necessary, in a case of emergency.

It is true that the tilting and turning bed was wider than the ordinary tilting bed, but it was designed for the comfort of acute patients, in particular those who had high lesions and those who were admitted with associated injuries. They admitted to Stoke Mandeville patients who had not only a severe fracture dislocation of the spine but associated injuries to the chest, ribs and scapula. They had at present a girl who had both scapulae broken. He did not need to say how difficult it was to turn such a patient manually by the staff, in particular at night. However, it might be possible to diminish the width of the bed in due course.

A very important point was the great difficulty every hospital in every country had today with staff, in particular at night time, and it was indeed a very great advantage just to turn the patient in such a bed, by pressing a button, whether he were paralysed or had had a brain operation or whether he were seriously ill from any other affliction.

\title{
DEMONSTRATION OF A SPECIAL ELECTRIC CONTROL FOR A POWER-DRIVEN WHEELCHAIR FOR HIGH SPINAL CORD LESIONS
}

\author{
By L. Guttmann and R. G. Maling \\ National Spinal Injuries Centre, Stoke Mandeville Hospital, Aylesbury, England
}

AN electric control for a power-driven wheelchair designed at the Electro-Mechanical Laboratory of the National Spinal Injuries Centre is demonstrated, whereby a patient with a very high cervical lesion can be made more independent. The young lady was admitted with a complete tetraplegia below $\mathrm{C}_{4}$. She was critically ill, had to have a tracheostomy done quickly, but fortunately she recovered to a certain extent as she has now some function of deltoid and biceps but no finger movements whatsoever. One does not need to stress how difficult it is to make patients with these high cervical lesions relatively independent. We have devised a gadget by which the patient with her left arm can control the chair quite easily.

The disadvantage for this level of lesion with the conventional power-drive chair is first of all that the joy-stick is operating against four micro-switches and, therefore, one has only on/off control. The speed is usually switched by two quite stiff toggle switches, both of which have to be moved to get one through four speed ranges. So, first of all the jerkiness caused by the simple micro-switches meant that above speed 2 the acceleration imparted by the motors threw the arm backward so there was then a tendency for the motor to switch on and off rapidly and the arm would go into oscillation. Therefore, we devised a system whereby the same joystick now controls two potentiometers, and these go to a transistorised device 